\title{
Reduced osteoblast activity in the mice lacking TR4 nuclear receptor leads to osteoporosis
}

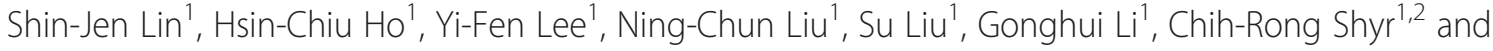 \\ Chawnshang Chang ${ }^{1,2^{*}}$
}

\begin{abstract}
Background: Early studies suggested that TR4 nuclear receptor might play important roles in the skeletal development, yet its detailed mechanism remains unclear.

Methods: We generated TR4 knockout mice and compared skeletal development with their wild type littermates. Primary bone marrow cells were cultured and we assayed bone differentiation by alkaline phosphatase and alizarin red staining. Primary calvaria were cultured and osteoblastic marker genes were detected by quantitative PCR. Luciferase reporter assays, chromatin immunoprecipitation (ChIP) assays, and electrophoretic mobility shift assays (EMSA) were performed to demonstrate TR4 can directly regulate bone differentiation marker osteocalcin.

Results: We first found mice lacking TR4 might develop osteoporosis. We then found that osteoblast progenitor cells isolated from bone marrow of TR4 knockout mice displayed reduced osteoblast differentiation capacity and calcification. Osteoblast primary cultures from TR4 knockout mice calvaria also showed higher proliferation rates indicating lower osteoblast differentiation ability in mice after loss of TR4. Mechanism dissection found the expression of osteoblast markers genes, such as ALP, type I collagen alpha 1, osteocalcin, PTH, and PTHR was dramatically reduced in osteoblasts from TR4 knockout mice as compared to those from TR4 wild type mice. In vitro cell line studies with luciferase reporter assay, ChIP assay, and EMSA further demonstrated TR4 could bind directly to the promoter region of osteocalcin gene and induce its gene expression at the transcriptional level in a dose dependent manner.

Conclusions: Together, these results demonstrate TR4 may function as a novel transcriptional factor to play pathophysiological roles in maintaining normal osteoblast activity during the bone development and remodeling, and disruption of TR4 function may result in multiple skeletal abnormalities.
\end{abstract}

Keywords: TR4, Nuclear receptor, Bone, Osteoporosis

\section{Background}

The TR4 nuclear receptor belongs to the nuclear receptor superfamily, which is comprised of transcription factors that are related by sequence and structure [1]. As transcription factors, nuclear receptors control the expression of target genes and thereby direct developmental, physiological, and behavioral responses from the cellular level to that of the whole organism. TR4 is closely related to the TR2, retinoid $\mathrm{X}$ receptor, COUP-TF, and HNF4 in sequence and structure [2], and all of them bind to AGGTCA DNA sequence motifs

\footnotetext{
* Correspondence: chang@urmc.rochester.edu
${ }^{1}$ George Whipple Lab for Cancer Research, Departments of Pathology,

* Correspondence: chang@urmc.rochester.edu
'George Whipple Lab for Cancer Research, Departments of Pathology,

Urology, Radiation Oncology, and The Wilmot Cancer center, University of Rochester Medical Center, Rochester, NY 14642, USA

${ }^{2}$ Sex Hormone Research Center, China Medical University/Hospital, Taichung 404, Taiwan
}

(c) 2012 Lin et al.; licensee BioMed Central Ltd. This is an Open Access article distributed under the terms of the Creative Commons Attribution License (http://creativecommons.org/licenses/by/2.0), which permits unrestricted use, distribution, and reproduction in any medium, provided the original work is properly cited. in direct repeat (DR) orientation, with variable spacing, in the promoters of their target genes [1,3-6]. Via knocking out TR4 $\left(\right.$ TR4 $^{-/}$), a complex set of phenotypic abnormalities were found to exist in the TR4 ${ }^{-/-}$mouse, including significant growth retardation [7], defects in female reproductive function [8] and maternal behavior [7], impaired cerebella function $[9,10]$, reduced sperm production [11], and reduced myelination [12], as well as abnormalities in glucose [13], lipid metabolism [14], and foam cell formation [15].

In this study, we reported that TR4 is involved in regulation of osteoblast activity via regulating osteocalcin expression. TR4 might represent a novel transcriptional factor involved in the bone remodeling network and provide a potential linkage to the pathogenesis of osteoporosis in human disease. 


\section{Methods}

\section{Mouse studies}

All animal procedures were approved by the Animal Care and Use Committee of the University of Rochester. $\mathrm{TR} 4^{-1-}$ mice used in this study were generated from heterozygous breeding pairs provided by Lexicon Genetics and genotyped as previously described [16].

\section{Cell culture}

Bone marrow cells were isolated from 10 weeks old TR4 wild type $\left(\mathrm{TR}^{+/+}\right)$and $\mathrm{TR} 4^{-/-}$mice. Cells were cultured in $2 \mathrm{~mL}$ of a modified essential medium ( $\alpha$-MEM) containing $10 \%$ fetal bovine serum (FBS) at $5 \times 10^{6}$ cells/well in 6 -well plates. After 7 days in culture, the media was replaced with media containing $10 \mathrm{mM} \beta$-glycerophosphate and $50 \mathrm{mg} /$ $\mathrm{mL}$ ascorbic acid. This media was changed every 2 days thereafter. On day 21 after plating, cells were fixed for alkaline phosphatase (ALP) and alizarin red staining or harvested for mRNA isolation using the RNeasy Mini Kit (Qiagen).

Mouse calvaria cells were obtained from neonatal mice 24 days after birth using sequential collagenease digestion. Briefly, calvaria were digested with trypsin/EDTA, then
$1 \mathrm{mg} / \mathrm{mL}$ collagenase. Cells were collected by centrifugation, and cultured in proliferation media (DMEM with 20\% FBS). Calvaria cells were cultured until $80 \%$ confluence and proliferation media was replaced by differentiation media $(\alpha-$ MEM containing 10\% FCS, $2 \mathrm{mmol} / \mathrm{L}$ glutamine, $50 \mathrm{mg} / \mathrm{mL}$ ascorbic acid, and $10 \mathrm{mmol} / \mathrm{L}$ b-glycerol phosphate).

\section{Real-time PCR}

Total RNA was isolated from TR4 $4^{-/-}$and TR4 ${ }^{+/+}$mice calvaria cultures using TRIzol Reagent (Invitrogen). The relative abundance of target mRNA was quantified relative to the control $\beta$-actin gene expression from the same reaction. Real-time PCR quantification amplifications of reversetranscribed first strand DNA samples were performed using the iCycler iQ PCR cycler (Bio-Rad). Relative quantification of PCR products were based on value differences between the target and $\beta$-actin control using the $2^{\Delta \Delta C T}$ method.

\section{The electrophoretic mobility shift assay (EMSA) \&} chromatin immunoprecipitation (ChIP) assay

TR4 protein for EMSA was transcribed and translated in TNT reticulocyte lysates (Promega). For the antibody super

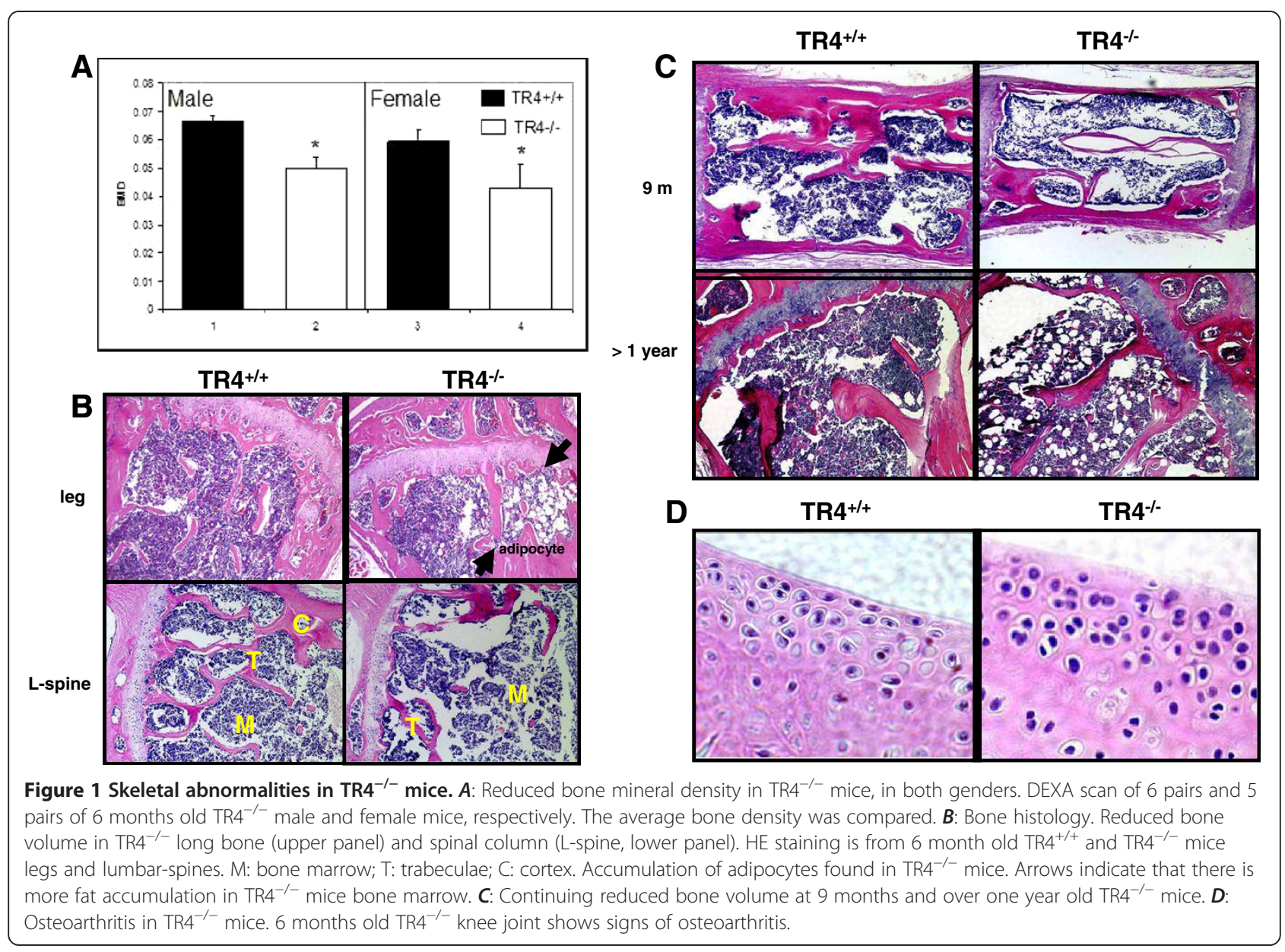




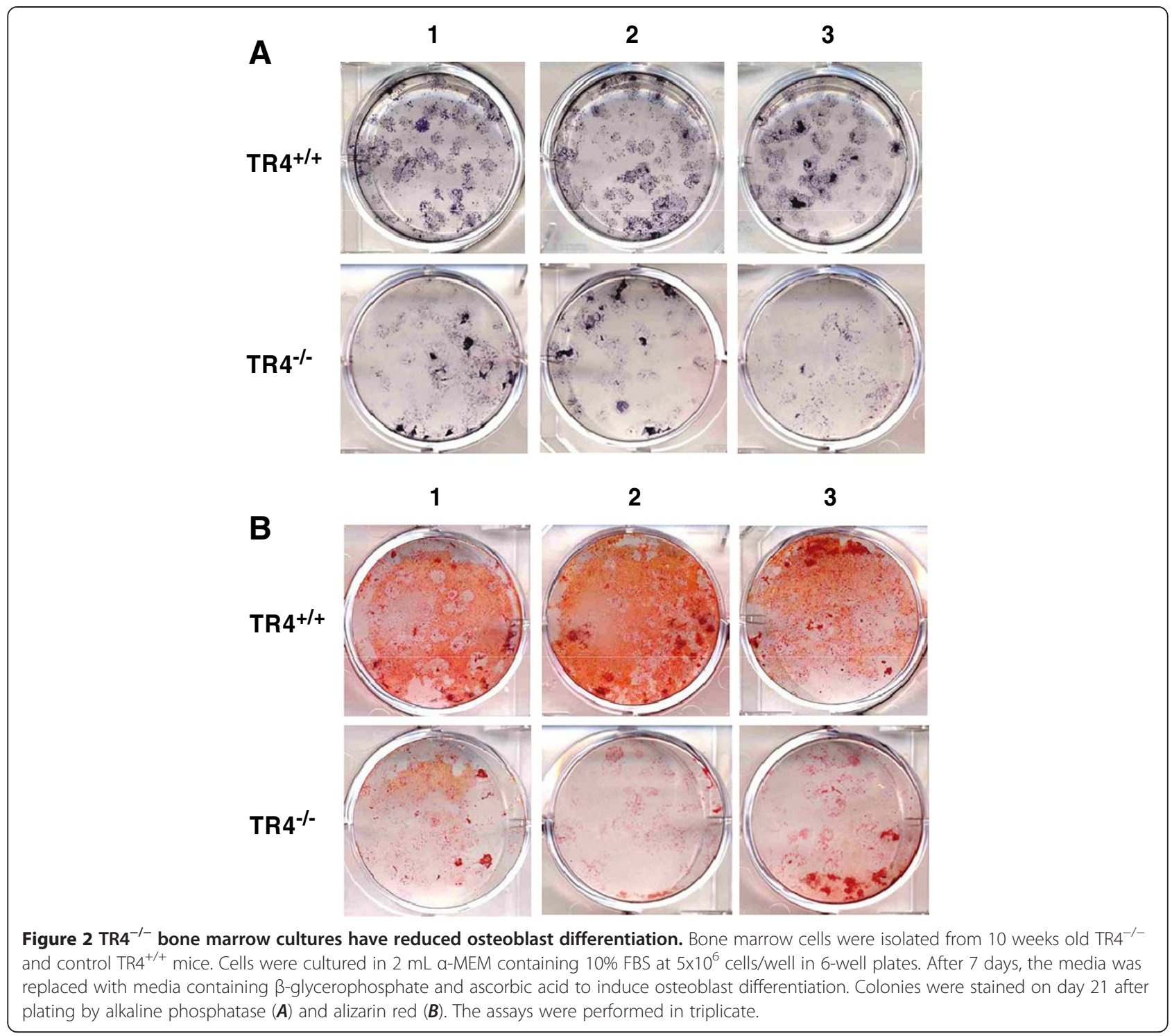

shift assay, the mixtures were incubated for $15 \mathrm{~min}$ in the presence or absence of a mouse anti-TR4 monoclonal antibody. The protein/DNA complexes were analyzed on a $5 \%$ native polyacrylamide gel. The results were visualized by autoradiography (Storm PhosphorImaging System, Amersham Pharmacia).

ChIP assays were performed in MC3T3 cells. Immunoprecipitations were performed at $4^{\circ} \mathrm{C}$ overnight, with $2 \mu \mathrm{g}$ monoclonal antibody.

\section{Bone tissue preparation}

The femurs were collected and excess muscle and soft tissues were excised. The bone specimens were fixed in $10 \%$ neutral buffered formalin. The specimens were decalcified for 21 days in 14\% EDTA (pH 7.2), embedded in paraffin, and sectioned at thickness of $3 \mu \mathrm{m}$. The sections were stained as described previously [17].

\section{Results}

\section{Mice lacking TR4 develop skeletal abnormalities}

Knockout of TR4 in mice results in growth retardation with reduction of circulating growth hormone [16]. One of the possible mechanisms is through regulation of skeletal growth. However, skeletal abnormalities can result from a direct effect on bone formation or remodeling. Clinically, the decreased bone mass observed in age-related osteoporosis is often accompanied by increased marrow adipose tissue. We found mice lacking TR4 might develop osteoporosis. As shown in Figure 1A, DEXA scan of TR4 ${ }^{+/+}$ and $\mathrm{TR}^{-1-}$ mice at 6 months of age revealed a significant reduction in bone mineral density in both male and female mice. Bone histology of $\mathrm{TR}^{-/-}$trabecular bone showed significant increased marrow adipocyte deposits (Figure 1B, upper panel, arrows). In addition, reduced bone volume was found in the spinal column (L-spine) of the 
$\mathrm{TR}^{-/-}$mice as compared to $\mathrm{TR} 4^{+/+}$mice (Figure 1B, lower panel). Reduced trabecular bone volume and increased adipocyte deposits were also found in 9 months old and over a year old TR4 $4^{-/-}$mice (Figure $1 C$ ). Interestingly, a few TR4 ${ }^{-/-}$mice at age of 6 months also started to develop signs of osteoarthritis with increasing superficial zone cells and disruption of articular surface. (Figure 1D). Together, results from Figure 1A-D suggest loss of TR4 may lead to the development of skeletal abnormalities.

\section{Reduced osteoblast differentiation in $\mathrm{TR}^{-/-}$mice}

All above observed skeletal abnormal phenotypes suggest that the $\mathrm{TR}^{-/-}$mice may develop accelerated bone loss, which is similar to human osteoporosis. To determine whether TR4 has a direct impact on the osteoblastic activity, bone marrow progenitor cells extracted from TR $4^{-1-}$ and $\mathrm{TR}^{+/+}$mice were isolated and placed in culture for colony formation assays. After 7 days, osteogenic media containing $\beta$-glycerol-phosphate and ascorbic acid was added to the cultures. ALP and alizarin red staining was performed, and ALP staining showed fewer colonies formed with reduced ALP density present in the TR4 ${ }^{-/-}$ bone marrow cells as compared to $\mathrm{TR} 4^{+/+}$littermates (Figure 2A). Similarly, alizarin red staining was decreased in the $\mathrm{TR} 4^{-/-}$bone marrow cells compared with $\mathrm{TR} 4^{+/+}$ control (Figure 2B). Together, results from Figure 2A-B suggests TR4 can regulate bone differentiation.

\section{Reduction of osteoblastic differentiation and associated genes in calvaria from $\mathrm{TR}^{-/-}$mice}

To further confirm TR4 roles in osteoblast differentiation, primary osteoblasts from 2-4 day old TR $4^{-/-}$mice $v s$. $\mathrm{TR}^{+/+}$mice calvaria were isolated and cultured. Cell proliferation rates were compared with different seeding densities (from $2 \times 10^{4}-1 \times 10^{5}$ cells), and results showed that calvaria cells from $\mathrm{TR}^{-1-}$ mice had higher proliferation rates than those from $\mathrm{TR}_{4}^{+/+}$mice, indicating lower osteoblast differentiation ability in TR4 ${ }^{-/-}$mice (Figure $3 \mathrm{~A}$ ).

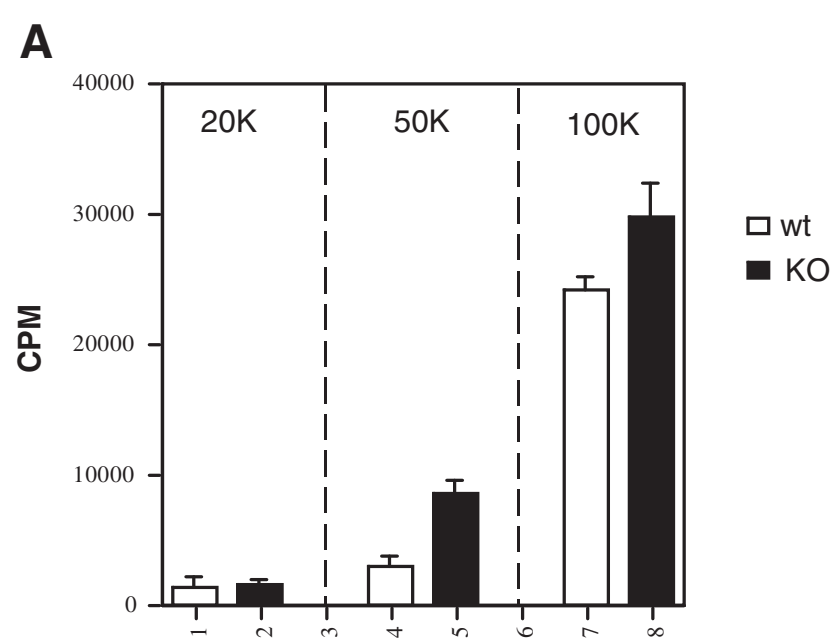

B
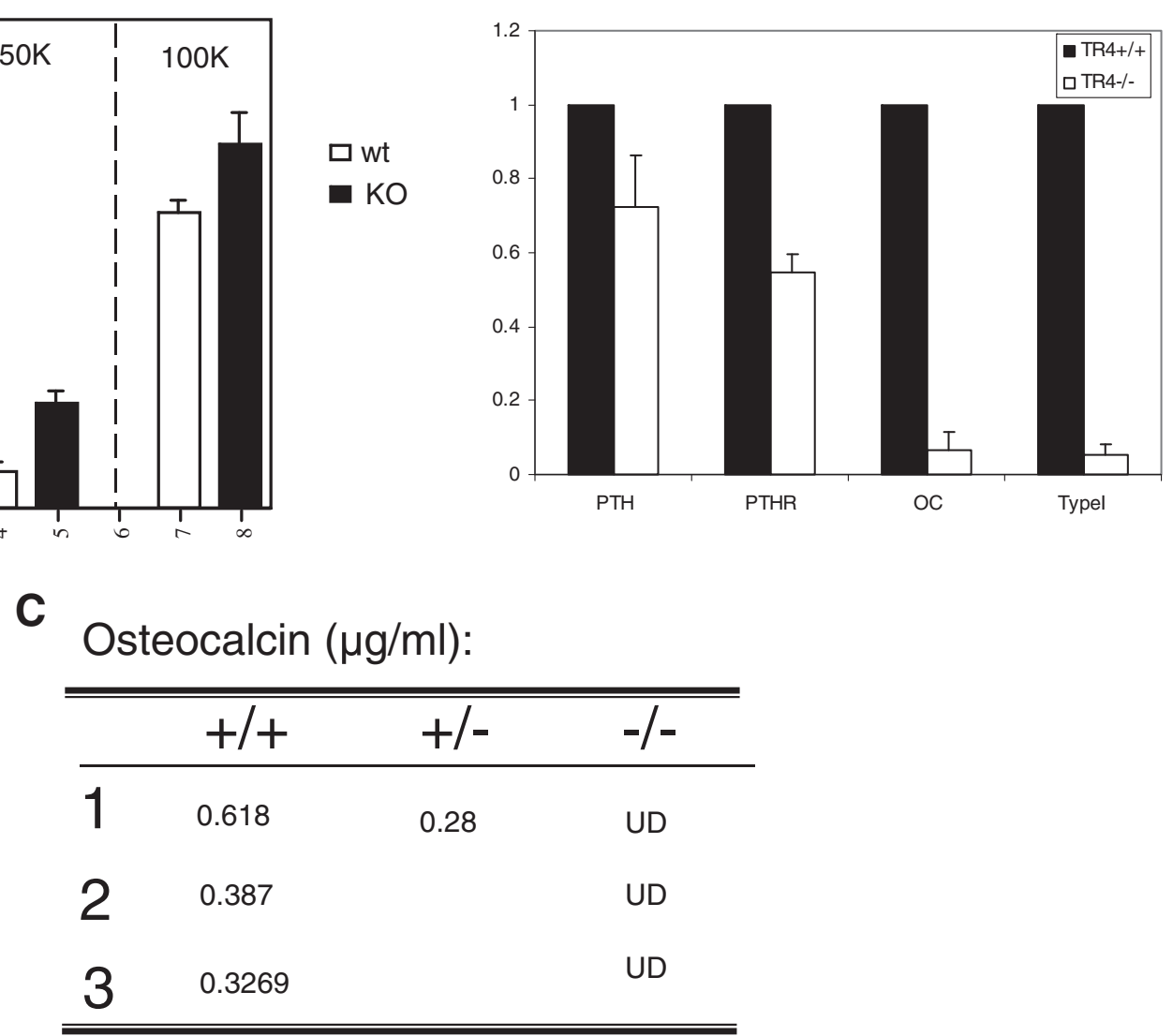

Figure 3 Characterization of primary calvaria cultures from $\mathrm{TR}^{-/-}$vs. $\mathrm{TR}^{+/+}$mice. A: Proliferation rate was compared between primary calvaria cultures of $\mathrm{TR}^{-/-}$and $\mathrm{TR}^{+/+}$pups by ${ }^{3} \mathrm{H}$-thymidine incorporation assay. The $20 \mathrm{~K}, 50 \mathrm{~K}$, and $100 \mathrm{~K}$ numbers represent different cell number seeding density. $\boldsymbol{B}$ : Quantification of osteoblastic marker gene expression. Total RNA were harvested from the primary calvaria cells of $\mathrm{TR}^{-/-}$and TR4 ${ }^{+/+}$mice, and converted to first strand CDNA, and subjected to q-PCR. The relative expression fold of the genes from TR4 ${ }^{-/}$mice,

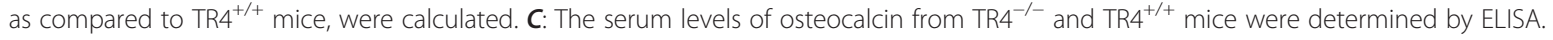


Quantitative real-time PCR analysis was then performed to determine the expression of genes associated with osteoblast activity. As shown in Figure 3B, all the expression levels of osteoblast marker genes, including PTH, PTHR, osteocalcin, and type I collagen alpha 1 were found to be dramatically reduced in osteoblasts from $\mathrm{TR} 4^{-/-}$mice as compared to those from $\mathrm{TR}^{+/+}$mice. This reduction of osteoblastic gene expression also reflected undetectable serum concentrations of osteocalcin, a bio-marker for osteoblast activity, found in TR4 ${ }^{-1-}$ mice (Figure 3C), suggesting TR4 may be able to regulate bone differentiation through those differentiation markers.

TR4 modulates osteocalcin gene at transcriptional level To further dissect the molecular mechanism by which TR4 can modulate those osteoblast marker genes, we focused on the osteocalcin gene regulation, since osteocalcin is secreted only by osteoblasts and thought to play an important role in the regulation of osteoblastic activity in bone mineralization and calcium ion homeostasis [18,19]. As a transcriptional factor, TR4 is known to bind to AGGTCA-like DR motif located in the targeted gene's promoter region to regulate its expression. It has been reported that the 5 '-promoter region of the osteocalcin gene contains the DR3 motif that can be bound and regulated by vitamin D receptor (VDR). This DR3 motif is highly conserved among species and the sequences are very similar among rat, mouse, and human promoters [20,21]. Since TR4 and VDR share the same response element [5], it is possible that TR4 can also bind and regulate osteocalcin at the transcriptional level. As shown in Figure 4A, TR4 induced osteocalcin promoter luciferase (OC-Luc) activity in a dose-dependent manner. Cbfa, a known osteocalcin transcriptional factor [22], was used as a positive control.

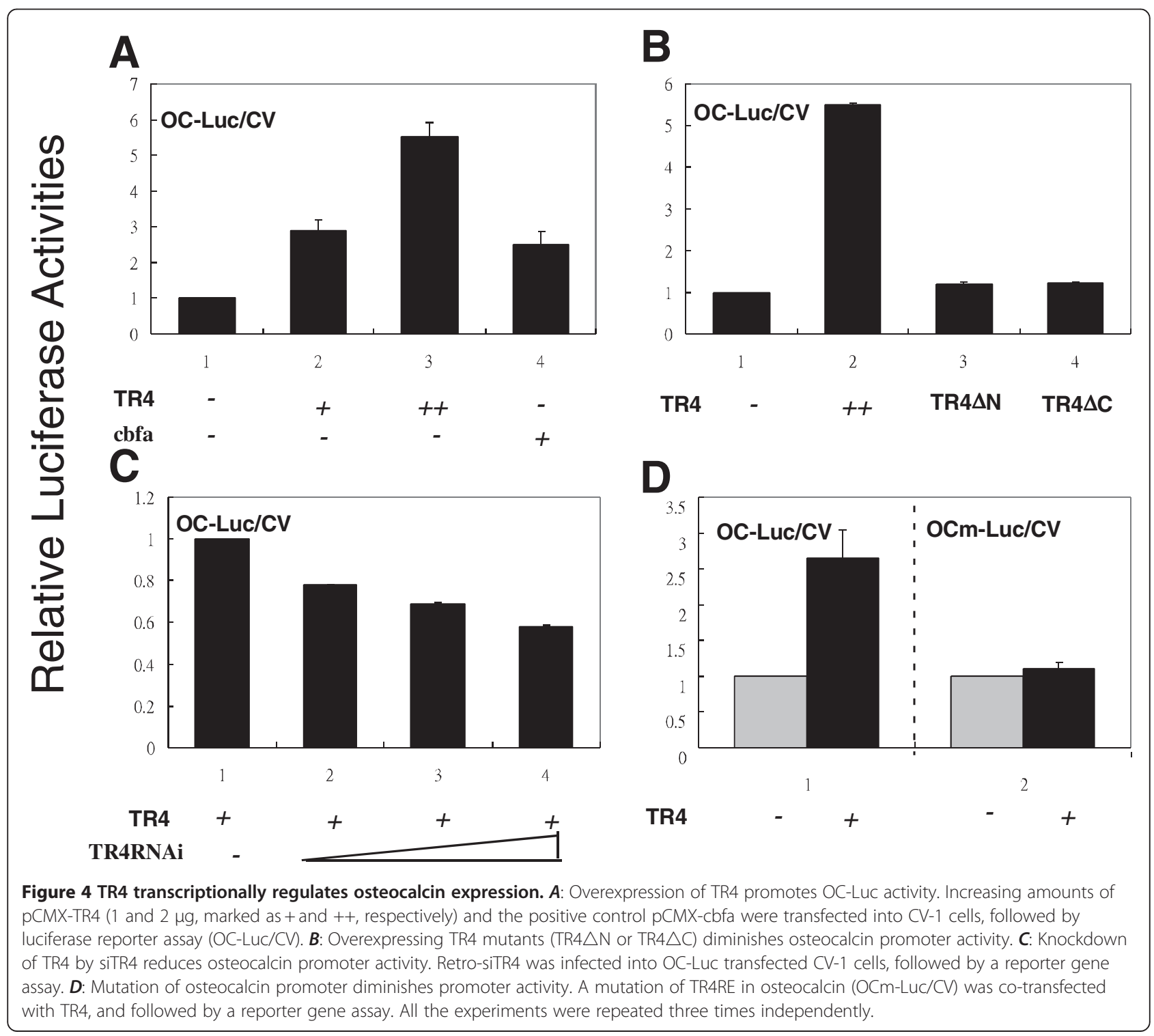


Furthermore, we found deletion of the $\mathrm{N}$ - and $\mathrm{C}$ terminals of TR4 (TR4 $\triangle N$ and TR4 $\triangle \mathrm{C}$, respectively) resulted in loss of the TR4 ability to transactivate OC-Luc (Figure 4B), suggesting the full-length of TR4 is required for this regulation. This conclusion was further confirmed showing TR4-mediated osteocalcin promoter transcriptional activation was reduced in the TR4-siRNA knockdown cells in a dose dependent manner (Figure 4C). Importantly, as the third $\mathrm{G}$ within the DR motif is important for TR4 binding, we therefore mutated this position from GGGTGAatgAGGACA to GGATGAatgAGTACA and as expected, we found mutated TR4RE in OC-Luc (OCm-Luc) was no longer able to transactivate luciferase activity (Figure 4D).

Together, results from Figure 4A-D suggested that TR4 modulated bone formation via regulating osteocalcin gene expression at the transcriptional level.

TR4 binds to the regulatory sequence of osteocalcin gene in vitro and in vivo

To further prove TR4 can bind directly to this DR3 DNA fragment, the TR4 response element (TR4RE) that is located at -465 to -437 of the osteocalcin promoter, we performed ChIP assay. As shown in Figure 5A, TR4 antibody, but not IgG control, could pull-down the DNAprotein complex containing the DR3 that could be amplified by the specific primers covering that region.

To further test the TR4-TR4RE interaction in vitro, EMSA was applied. As shown in Figure 5B, TR4 can form a complex with TR4RE, and this TR4-TR4RE can be super shifted by adding TR4 antibody (lane 2) [4]. The specific TR4-DNA-protein complex was further competed out by $100 \mathrm{X}$ unlabeled TR4RE (lane 3), but not mutant TR4RE (TR4REm) (lane 4 and 5), suggesting TR4 can physically bind to osteocalcin promoter region to transcribe its expression.

\section{Discussion}

We found that TR4 directly influences osteoblast activity with reduced osteoblast differentiation found in bone marrow progenitor cells isolated from $\mathrm{TR}^{-1-}$ mice as compared to $\mathrm{TR}^{+/+}$mice. This reduction of bone marrow progenitor cells differentiation could then contribute to osteoporosis developed in their later life. Our data are in agreement with the critical role of bone marrow progenitor cells in the senile osteoporosis where depletion and/or inhibition of bone marrow progenitor cells differentiation and activation could cause osteoporosis. TR4 represents a novel factor that controls differentiation of bone marrow progenitor cells allowing for osteoblast formation. And the depletion of TR4 in mice results in premature aging accompanied with osteoporosis in both genders. TR $4^{-1-}$ mice display a significant adipocyte accumulation in their trabecular bones, indicating that blocking TR4 function can also alter the balance between adipogenesis and osteogenesis, and that bone formation is inhibited. These findings make TR4 a candidate gene to monitor bone activity.

TR4 transcript levels did not alter when undifferentiated embryonic stem cells were induced into adipocytes and osteoblasts [23], suggesting that the environmental/ exogenous factors that control TR4 activity might be critical for controlling the bone marrow progenitor cells activity to affect osteoblast differentiation. Therefore, identifying its upstream modulator(s) offers novel therapeutic and/or preventive approaches to target senile osteoporosis. However, in contrast to TR4, it is reported
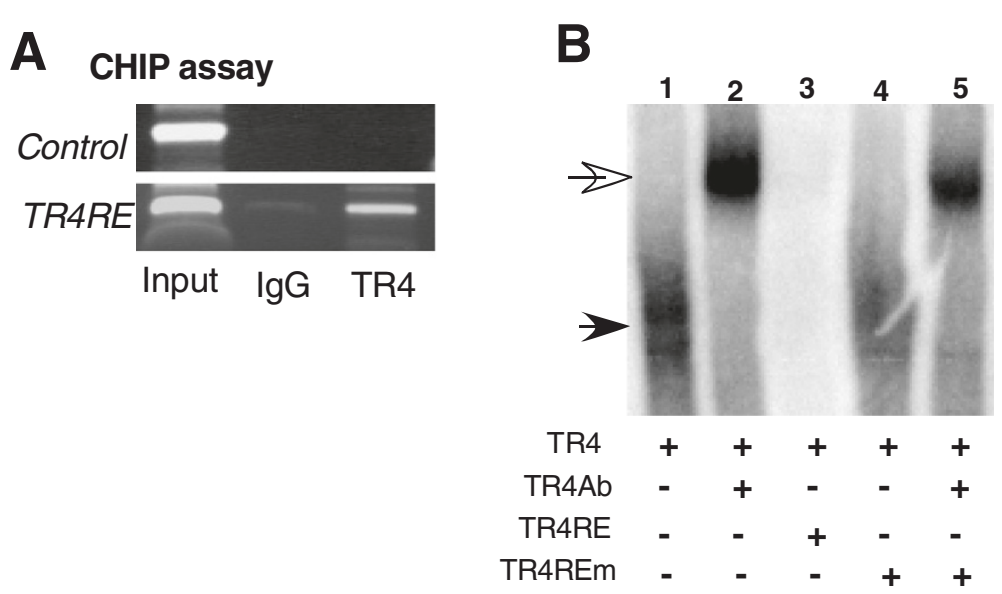

Figure 5 TR4 binds to TR4RE in osteocalcin promoter. $\boldsymbol{A}$ : The binding of TR4 to TR4RE (DR3) in osteocalcin was demonstrated by ChIP assay. Anti-TR4 antibody was used to pull-down the DNA-protein complex, and binding sequence was amplified by the specific primers that cover the TR4RE. B: EMSA. TR4 proteins were translated by TNT rabbit reticular lysate and applied to the gel shift assay. The probe (TR4RE) was labeled with ${ }^{32} \mathrm{P}$, and TR4 antibody was used for the super shift (lane 2). $100 \times$ cold competition with wild type TR4RE (lane 3), or TR4REm (lane 4, 5) were applied. 
that attenuation of PPAR gamma function could promote osteogenesis, such that bone formation can be enhanced [24]. Since both TR4 and PPAR gamma are members of the nuclear receptor superfamily and share the similar regulatory DNA response elements and some upstream modulator(s), it will be of interest to dissect the activity/specificity of both receptors in the process of early bone marrow progenitor cells differentiation that might have a great impact on the osteoblast activity.

\section{Conclusions}

Together, these results demonstrate TR4 may function as a novel transcriptional factor to play its pathophysiological roles in maintaining normal osteoblast activity during the bone development and remodeling, and disruption of TR4 function may result in multiple skeletal abnormalities.

\section{Competing interests}

The authors declare that they have no competing interests.

\section{Authors' contributions}

ShL participated in the in vivo and in vitro assays and drafted the manuscript. $\mathrm{HH}$ carried out the in vivo and in vitro assays. YL participated in experimental design and drafted the manuscript. NL carried out the in vitro assays. SuL participated in experimental design. GL and CS participated in experimental design and discussion. CC conceived of the study, and participated in its design and coordination and helped to draft the manuscript. All authors read and approved the final manuscript.

\section{Acknowledgments}

This work was supported by George Whipple Professorship endowment, NIH Grants CA127548 and CA156780, and Taiwan Department of Health Clinical Trial and Research Center of Excellence Grant DOH99-TD-B-111-004 (china Medical University, Taichung, Taiwan).

Received: 18 February 2012 Accepted: 29 May 2012

Published: 7 June 2012

\section{References}

1. Lee YF, Lee HJ, Chang C: Recent advances in the TR2 and TR4 orphan receptors of the nuclear receptor superfamily. J Steroid Biochem Mol Biol 2002, 81(4-5):291-308

2. Chang C, Da Silva SL, Ideta R, Lee YF, Yeh S, Burbach JPH: Human and rat TR4 orphan receptors specify a subclass of the steroid receptor superfamily. Proceedings of the National Academy of Sciences USA 1994, 1994:6040-6044.

3. Lee YF, Pan HJ, Burbach PH, Morkin E, Chang C: Identification of direct repeat 4 as a positive regulatory element for the human TR4 orphan receptor: a modulator for the thyroid hormone target genes. J Biol Chem 1997, 272:12215-12220.

4. Lee YF, Young WJ, Burbach JPH, Chang C: Negative feedback control of the retinoid-retinoic acid/retinoid $X$ receptor pathway by the human TR4 orphan receptor, a member of the steroid receptor superfamily. J Biol Chem 1998, 273:13437-13443.

5. Lee YF, Young WJ, Lin WJ, Shyr CR, Chang C: Differential regulation of direct repeat 3 vitamin $D 3$ and direct repeat 4 thyroid hormone signaling pathways by the human TR4 orphan receptor. J Biol Chem 1999, 274:16198-16205.

6. Lee Y-F, Shyr CR, Thin TH, Lin WJ, Chang C: Convergence of two repressors through heterodimer formation of androgen receptor and testicular orphan receptor-4: a unique signaling pathway in the steroid receptor superfamily. Proceedings of the National Academy of Sciences USA 1999, 96:14724-14729.

7. Collins LL, Lee YF, Heinlein CA, Liu NC, Chen YT, Shyr CR, Meshul CK, Uno H, Platt KA, Chang C: Growth retardation and abnormal maternal behavior in mice lacking testicular orphan nuclear receptor 4. Proc Natl Acad Sci USA 2004, 101(42):15058-15063.
8. Chen LM, Wang RS, Lee YF, Liu NC, Chang YJ, Wu CC, Xie S, Hung YC, Chang C: Subfertility with defective folliculogenesis in female mice lacking testicular orphan nuclear receptor 4. Mol Endocrinol 2008, 22(4):858-867.

9. Chen $Y T$, Collins $L L$, Uno H, Chang C: Deficits in motor coordination with aberrant cerebellar development in mice lacking testicular orphan nuclear receptor 4. Mol Cell Biol 2005, 25(7):2722-2732.

10. Chen YT, Collins LL, Chang SS, Chang C: The roles of testicular orphan nuclear receptor 4 (TR4) in cerebellar development. Cerebellum 2008, 7(1):9-17.

11. Mu X, Lee Y, Liu N, Chen Y, Kim E, Shyr C, Chang C: Targeted inactivation of Testicular nuclear Orphan Receptor 4 delays and disrupts late meiotic prophase and subsequent meiotic divisions of spermatogenesis. Mol Cell Biochem 2004, 24:5887-5899.

12. Zhang Y, Chen YT, Xie S, Wang L, Lee YF, Chang SS, Chang C: Loss of testicular orphan receptor 4 impairs normal myelination in mouse forebrain. Mol Endocrinol 2007. 21(4):908-920.

13. Liu NC, Lin WJ, Kim E, Collins LL, Lin HY, Yu IC, Sparks JD, Chen LM, Lee YF, Chang C: Loss of TR4 orphan nuclear receptor reduces phosphoenolpyruvate carboxykinase-mediated gluconeogenesis. Diabetes 2007, 56(12):2901-2909.

14. Kim E, Liu NC, Yu IC, Lin HY, Lee YF, Sparks JD, Chen LM, Chang C: Metformin inhibits nuclear receptor TR4-mediated hepatic stearoylcoenzyme a desaturase 1 gene expression with altered insulin sensitivity. Diabetes 2011, 60(5):1493-1503.

15. Xie S, Lee YF, Kim E, Chen LM, Ni J, Fang LY, Liu S, Lin SJ, Abe J, Berk B, et al: TR4 nuclear receptor functions as a fatty acid sensor to modulate CD36 expression and foam cell formation. Proc Natl Acad Sci U S A 2009, 106(32):13353-13358.

16. Collins LL, Lee YF, Heinlein CA, Liu NC, Chen YT, Shyr CR, Meshul CK, Uno H, Platt KA, Chang C: Growth retardation and abnormal maternal behavior in mice lacking testicular orphan nuclear receptor 4. Proc Natl Acad Sci U S A 2004, 101(42):15058-15063.

17. Zhang X, Schwarz EM, Young DA, Puzas JE, Rosier RN, O'Keefe RJ: Cyclooxygenase-2 regulates mesenchymal cell differentiation into the osteoblast lineage and is critically involved in bone repair. J Clin Invest 2002, 109(11):1405-1415.

18. Roy ME, Nishimoto SK, Rho JY, Bhattacharya SK, Lin JS, Pharr GM: Correlations between osteocalcin content, degree of mineralization, and mechanical properties of C. carpio rib bone. J Biomed Mater Res 2001, 54(4)):547-553.

19. Lee NK, Sowa H, Hinoi E, Ferron M, Ahn JD, Confavreux C, Dacquin R, Mee PJ, McKee MD, Jung DY, et al: Endocrine regulation of energy metabolism by the skeleton. Cell 2007, 130(3):456-469.

20. Gutierrez S, Liu J, Javed A, Montecino M, Stein GS, Lian JB, Stein JL: The vitamin $D$ response element in the distal osteocalcin promoter contributes to chromatin organization of the proximal regulatory domain. J Biol Chem 2004, 279(42):43581-43588.

21. Sierra J, Villagra A, Paredes R, Cruzat F, Gutierrez S, Javed A, Arriagada G, Olate J, Imschenetzky M, Van Wijnen AJ, et al: Regulation of the bonespecific osteocalcin gene by $\mathrm{p} 300$ requires Run $\times 2 / \mathrm{Cbfa} 1$ and the vitamin D3 receptor but not p300 intrinsic histone acetyltransferase activity. Mol Cell Biol 2003, 23(9):3339-3351.

22. Javed A, Gutierrez S, Montecino M, van Wijnen AJ, Stein JL, Stein GS, Lian JB: Multiple Cbfa/AML sites in the rat osteocalcin promoter are required for basal and vitamin D-responsive transcription and contribute to chromatin organization. Mol Cell Biol 1999, 19(11):7491-7500.

23. Shyr CR, Collins LL, Mu XM, Platt KA, Chang C: Spermatogenesis and testis development are normal in mice lacking testicular orphan nuclear receptor 2. Mol Cell Biol 2002, 22(13):4661-4666.

24. Kawai M, Rosen CJ: PPARgamma: a circadian transcription factor in adipogenesis and osteogenesis. Nat Rev Endocrinol 2010, 6(11):629-636.

doi:10.1186/1477-7827-10-43

Cite this article as: Lin et al:: Reduced osteoblast activity in the mice lacking TR4 nuclear receptor leads to osteoporosis. Reproductive Biology and Endocrinology 2012 10:43. 